an advantage even when translating between other languages.

The dictionary ends with a two-way index to the Cyrillic spelling of geographical names relevant to nuclear physics and technology. Herr Sube is to be congratulated on his enterprise and industry; one regrets only that the British publisher has seen fit to raise the price so high.

J. B. Sykes

\section{CHINESE PHYSICS}

Science and Civilisation in China

By Dr. Joseph Needham, with the collaboration of Dr. Wang Ling, and the special co-operation of Konneth Girdwood Robinson. Vol. 4: Physics and Physical Technology. Part 1: Physics. Pp.xxxiv + 434 + platos 96-123. (Cambridgo: At the University Press, 1962.) 84s. net.

THIS is the first part of the fourth volume of Needham's History of Science; it is concerned with physies. The main chapters treat of light, of sound and of magnetism. There are briefer sections on mass and mensuration, on dynamies, surface phenomena, heat, luminescence and electrostatics. It is a very comprehensive and woll-illustrated survoy.

Throughout the book the author is pre-occupied with the question why the Chinese did not develop scientific thoories in spite of tho many practical devices they invented. This failure is indeed as important for our understanding of science as the success in classical Greece. Dr. Needham suggests the lack of an alphabetic language as one reason. $\mathrm{He}_{e}$ romarks, too, that atomism is a crucial stage in the growth of physics which the Chineso never reached, while the Greeks very quickly arrived at it.

I think this is very true and, in fact, points to an explanation. After all, the growth of science is a natural phenomenon; it belongs to the mental, social and biological evolution of mankind. The dovelopment of a scientific idea is in some ways analogous to the process by which the individual human being, from infancy on, learns to cope with, and to know, reality. All our ideas arise from primitive phantasies that turn into myths and fables, and slowly become more refined, rational and even abstract. The history of mathematies, from Pythagorean number phantasies to formal axiomaties, is an obvious example. The progress of physics has certainly been in tho direction of ever-increasing abstraction that was made possible by the use of the steadily improving, mathematical symbolism. The symbolism was capable of improvement because the Pythagoreans represented number as a geometrical pattern. This enabled them to split their symbols into content and form, to 'formalize' them, and to repress the primitive phantasies attached to them originally. Thus a set of, more or less, empty symbols is obtained which can be filled with new contont, resulting from observation and experiment. Physics expanded through 'mathematization'; and science as a whole was enlarged, and made secure, through formal, logical reasoning which is the offspring of mathematies.

The Chinese idengrams are then clearly seen to be insufficient for the purposes of science; the symbols - thongh later turned into radicals - are too closely bound to their original, primitive meanings. They are schematized, but not sufficiently formalizable so as to allow the representation of experiences that are more complex and unusual-like the laboratory experiment-than those of everyday life. In physics, the Chinese started, as the Greeks did, with the concept of continuum. The Chhi and the Greek concept resemble each other, naturally; but the Greeks made their ideas moro and more abstract. Thus they managed to ovorcome the horror they felt concerning the idoa of change by seeing it as the motion of indestructible though invisible atoms in the void. This involved the idea of cause, aitia, which was abstracted from the primitive bolief in the inevitability of the relation of erime and punishment; and so an orderly, lawful cosmos was created that could be the object of sciontific inquiry. The path to the atom and to tho later pneuma was not straightforward as can be seen from the Pre-Socratic and Stoic writings. The Chinese never took it becanse they remained too closo to their original phantasies; they nover separated as sharply as the Wostern thinkers phantasy from fact, internal from external reality. This comes out clearly in the present book. Their greatest success-- the magnetic compass-always remained bound up with pseudo-science, with divination and geomancy even after it had been in use for the purposes of navigation.

Why did the Greeks succeed in subduing their phantasies and in becoming more rational while the Chinese failed ? One rcason may be this. The Greeks, at the crucial time in their development, managed to throw off the divinity of kingship and similar beliefs-and to institute (more or less) democratic régimes. The Chinose did so only in 1912.

The book, like its predecessors, is carefully edited and beautifully produced. It will give much pleasure and stimulation to the historian and philosopher of science.

ERnest H. HUTTEN

\section{THEORY OF THE SOLID STATE}

Wave Mechanics of Crystalline Solids

By Prof. R. A. Smith. Pp. xv +473 . (London: Chapman and Hall, Ltd., 1961.) 84s. not.

T.HE increasing scope and importance of solidstate physies has been accompanied by a rapid increase in the numbor of books on the subject. Prof. Smith's book has been written with a particular aim which makes it a particularly valuable addition to the list. To quote the blurb: "The underlying theory both of the forces which bind solids into their crystalline form and of the motion of charge carriers through the solids is by no means simple, and is frequently beyond the experience and training of experimental research workers in this field. The number of such workers is now very great and this book is an attempt to make some of the basic theory of crystalline solids moro readily available to experimental physicists and engineers. Its aim is to treat the fundamental theory of wave motion in solids, both that of the lattice and of the electrons, in as olementary a way as is possible".

In my opinion tho book is exceptionally succossful as a feat of lucid exposition of the elements of the subject - the standard theory of lattico vibrations and the motion of electrons in crystal lattices--which are covered in the early chapters of the book. The order and method of prosentation have been carefully thought out, simple models are studied in patient detail which is not allowed to become wearisome, points of difficulty are nevor hastily passed over or quietly ignorod, and (a particularly happy feature) the text contains a good number of oxercises chosen so as to 